\title{
Risk stratification for diabetic eye screening. Reply to Stratton I. M. and Aldington S. J. [letter]
}

\author{
H. C. Looker • S. O. Nyangoma • D. T. Cromie • J. A. Olson • G. P. Leese • S. Philip • \\ M. W. Black • J. Doig • N. Lee • A. Briggs • E. J. Hothersall • A. D. Morris • R. S. Lindsay • \\ J. A. McKnight • D. W. M. Pearson • N. A. Sattar • S. H. Wild • P. McKeigue • H. M. Colhoun • \\ on behalf of the Scottish Diabetes Research Network Epidemiology Group \\ and the Scottish Diabetic Retinopathy Collaborative
}

Received: 7 October 2013 / Accepted: 10 October 2013 /Published online: 8 November 2013

(C) Springer-Verlag Berlin Heidelberg 2013

To the Editor: We thank Drs Stratton and Aldington for their comments on our paper. Our manuscript [1] was in the late stages of review at the time of the publication of their paper [2].

We fully acknowledge as stated in our discussion that apparent regression of retinopathy can result from a variety of causes including true regression of disease, changes in the retina that are not captured in retinal photographs and inaccuracy of the actual grading. However, as also noted in our discussion, when we constrained models to allow only misclassification and no actual regression, the model fit was not as good as when the

H. C. Looker $(\bowtie) \cdot$ E. J. Hothersall • A. D. Morris · H. M. Colhoun Population Health Sciences, University of Dundee, The MacKenzie Building, Kirsty Semple Way, Dundee DD2 4BF, UK

e-mail: h.c.looker@dundee.ac.uk

\section{S. O. Nyangoma}

Centre for Cancer Prevention, Queen Mary University of London,

London, UK

\section{T. Cromie}

Department of Public Health, NHS Lanarkshire, Glasgow, UK

\section{J. A. Olson • D. W. M. Pearson}

Department of Medicine, Aberdeen Royal Infirmary, Aberdeen, UK

\section{G. P. Leese}

Department of Medicine, Ninewells Hospital and Medical School, Dundee, UK

\section{S. Philip}

Grampian Diabetes Research Unit, Aberdeen, UK

M. W. Black $\cdot$ N. Lee

Diabetic Retinopathy Screening Collaborative, NHS Highland, Inverness, UK model allowed for both misclassification and regression, so we do not think the regression noted in the paper is principally a result of issues with grading.

As stated in our paper [1], the Scottish Diabetic Retinopathy Screening (DRS) programme has a centralised quality controlled grading system. This is comprised of grading centres all working to a single grading scheme with robust internal and external quality assurance. A high standard of quality controlled grading is essential for any screening programme. We embrace this, and have published data documenting our quality assurance results [3], as cited in our

J. Doig

Department of Medicine, Forth Valley Royal Hospital, Larbert, UK

A. Briggs

Institute of Health \& Wellbeing, University of Glasgow,

Glasgow, UK

R. S. Lindsay $\cdot$ N. A. Sattar

British Heart Foundation Glasgow Cardiovascular Research Centre, University of Glasgow, Glasgow, UK

J. A. McKnight

Department of Medicine, Western General Hospital,

Edinburgh, UK

J. A. McKnight

College of Medicine \& Veterinary Medicine, University of

Edinburgh, Edinburgh, UK

S. H. Wild • P. McKeigue

Centre for Population Health Sciences, University of Edinburgh,

Edinburgh, UK

H. M. Colhoun

Department of Public Health, NHS Fife, Kirkcaldy, UK 
paper [1], and all screening centres in Scotland continue to undertake rigorous quality assurance within the programme.

In spring 2013, 84 graders from nine centres, including those using automated grading systems, participated in Scotland's biannual external quality assurance programme. At this time no cases of observable maculopathy, or observable background, referable background or proliferative retinopathy were misclassified as 'no retinopathy'. In cases where a grading of no retinopathy was recorded, the consensus standard was no retinopathy in $74.4 \%$ of cases, mild background in $13.2 \%$, referable maculopathy in $0.1 \%$ and technical failure in $0.3 \%$.

We also agree that all screening programmes, in general, and indeed any changes in the screening interval, should be closely monitored and that any programme switching to a longer interval for those with no evidence of disease at a previous examination would need to be confident in its grading criteria for 'no disease'.

As such, we are confident that the increased risk from lengthening screening intervals for diabetic retinopathy for patients with type 2 diabetes and no visible retinopathy at two successive annual screening exams is small, at least in Scotland, and expect that our study will help inform future decisions pertaining to the Scottish retinal screening programme.

Duality of interest The authors declare that there is no duality of interest associated with this manuscript.

Contribution statement All authors were responsible for drafting the letter or revising it critically for important intellectual content. All authors approved the version to be published.

\section{References}

1. Looker HC, Nyangoma SO, Cromie DT et al (2013) Predicted impact of extending the screening interval for diabetic retinopathy: the Scottish Diabetic Retinopathy Screening programme. Diabetologia 56:1716-1725

2. Stratton IM, Aldington SJ, Taylor DJ, Adler AI, Scanlon PH (2013) A simple risk stratification for time to development of sight-threatening diabetic retinopathy. Diabetes Care 36:580-585

3. Goatman KA, Philip S, Fleming AD et al (2012) External quality assurance for image grading in the Scottish Diabetic Retinopathy Screening Programme. Diabet Med 29:776-783 